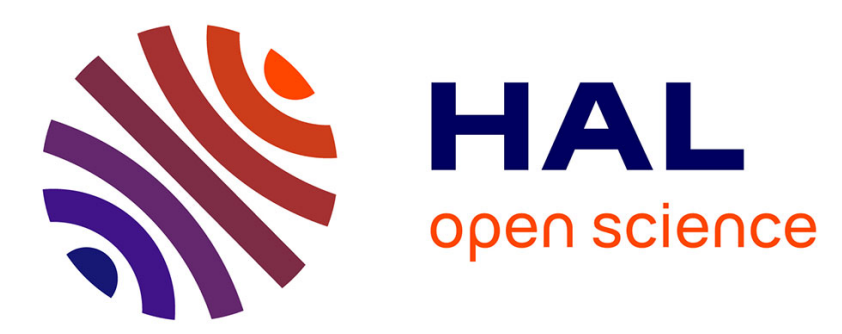

\title{
Using remotely sensed solar radiation data for reference evapotranspiration estimation at a daily time step
}

Benjamin Bois, Philippe Pieri, Cornelis van Leeuwen, Lucien Wald, Frédéric

Huard, Jean-Pierre Gaudillère, Etienne Saur

\section{- To cite this version:}

Benjamin Bois, Philippe Pieri, Cornelis van Leeuwen, Lucien Wald, Frédéric Huard, et al.. Using remotely sensed solar radiation data for reference evapotranspiration estimation at a daily time step. Agricultural and Forest Meteorology, 2007, 148 (4), pp.619-630. 10.1016/j.agrformet.2007.11.005 . hal-00335548

\section{HAL Id: hal-00335548 \\ https://hal.science/hal-00335548}

Submitted on 29 Nov 2008

HAL is a multi-disciplinary open access archive for the deposit and dissemination of scientific research documents, whether they are published or not. The documents may come from teaching and research institutions in France or abroad, or from public or private research centers.
L'archive ouverte pluridisciplinaire HAL, est destinée au dépôt et à la diffusion de documents scientifiques de niveau recherche, publiés ou non, émanant des établissements d'enseignement et de recherche français ou étrangers, des laboratoires publics ou privés. 


\title{
Using remotely sensed solar radiation data for reference evapotranspiration estimation at a daily time step
}

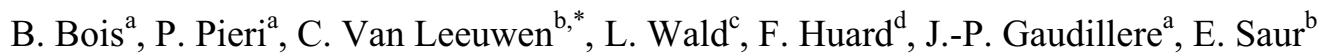 \\ ${ }^{a}$ UMR Ecophysiologie et Génomique Fonctionelle de la Vigne, ISVV, Université Bordeaux 2 - INRA, BP 81, \\ 33883 Villenave d'Ornon Cedex, France \\ ${ }^{b}$ Ecole Nationale d'Ingénieurs des Travaux Agricoles de Bordeaux, 1 cours du Général de Gaulle, 33175 \\ Gradignan Cedex, France \\ ${ }^{c}$ CEP, Ecole de Mines de Paris, BP 207, F-06904 Sophia Antipolis Cedex, France \\ ${ }^{d}$ UE AgroClim, INRA, Domaine de Saint-Paul, Site Agroparc, 84914 Avignon Cedex 9, France
}

*Corresponding author, Tel.: +33 5573507 55; Fax: +33 5573507 59. Email: k-van-leeuwen@enitab.fr

\begin{abstract}
Solar radiation is an important climatic variable for assessing reference evapotranspiration $\left(E_{0}\right)$, but it is seldom available in weather station records. Meteosat satellite images processed with the Heliosat-2 method provide the HelioClim-1 database, which displays spatialized solar radiation data at a daily time step for Europe and Africa. The aim of the present work was to investigate the interest of satellite-sensed solar radiation for $E_{0}$ calculation, where air temperature is the sole local weather data available. There were two study areas in Southern France. One (Southwest, SW) is characterized by oceanic climate and the other (Southeast, SE) by Mediterranean climate. A data set of daily values for 19 weather stations spanning five years (2000-2004) was used. First, a sensitivity analysis of the Penman-Monteith formula to climate input variables was performed, using the Sobol' method. It shows that $E_{0}$ is mainly governed by solar radiation during summer, and by wind speed during winter. Uncertainties of HelioClim-1 solar radiation data and their repercussions on $E_{0}$ formulae were evaluated, using the FAO-56 Penman-Monteith formulae $(P M)$ and radiation-based methods (Turc, $T U$; Priestley-Taylor, $P T$ and Hargreaves-Radiation, $H R$ ). It was shown that HelioClim-1 data slightly underestimate solar radiation and provide relative RMSE (root mean squared error) of $20 \%$ of the mean annual value for SW and $14 \%$ for SE. The propagation of HelioClim-1 data uncertainties is small in $P M$ but considerable in radiation methods. Four estimation methods were then compared to $P M$ data: the 1985 Hargreaves formula (HT) based on air temperature only; $T U, P T$ and $H R$, based on air temperature and satellite sensed solar radiation. Radiation methods were more precise and more accurate than $H T$, with RMSE ranging from $0.52 \mathrm{~mm}$ to $0.86 \mathrm{~mm}$ against $0.67 \mathrm{~mm}$ to $0.96 \mathrm{~mm}$. These results suggest that using satellite-sensed solar radiation may improve $E_{0}$ estimates for areas where air temperature is the only available record at ground level.
\end{abstract}

Keywords: evapotranspiration, solar radiation, Penman-Monteith equation, sensitivity analysis, remote sensing.

\section{Introduction}

Reference evapotranspiration $\left(E_{0}\right)$ is an agrometeorological variable widely used in hydrology and agriculture. Together with precipitation, it is a major input in soil water balance models. Several of these models require daily or hourly evapotranspiration data to provide acceptable estimate of plants water requirements (Brisson et al., 1992 ; Guyot, 1997 ; Lebon et al., 2003). Penman-Monteith combination method is one of the most accurate methods to evaluate $E_{0}$ at different time steps. A standardization of this method has been proposed by the Food and Agriculture Organization (Allen et al., 1998). It is known as FAO- 
56 Penman-Monteith application, and it can be considered as a worldwide standard. However, it requires numerous weather variables (air temperature, relative humidity, wind speed and solar radiation), which are seldom available in basic meteorological records. Consequently, reference evapotranspiration is often estimated by means of empirical equations based on air temperature, relative humidity, extraterrestrial radiation and/or precipitation (Droogers and Allen, 2002 ; Hargreaves et al., 1985 ; Popova et al., 2005 ; Turc, 1961). Several authors proposed modifications of existing empirical methods (Droogers and Allen, 2002 ; Gavilan et al., 2006 ; Pereira, 2004 ; Pereira and Pruitt, 2004 ; Popova et al., 2005 ; Xu and Singh, 2002). The accuracy of these methods remains acceptable when applied at large time and space scales (e.g., a decade and distances larger than $1000 \mathrm{~km}$ ). However, empirical formulae are limited by their inherent characteristics. The lack of one, or more, climate variable physically related to evaporation and transpiration processes inescapably reduces the accuracy of evapotranspiration estimation. Even if recalibration of empirical factors may improve locally the precision of these methods, considerable estimation errors will remain as time variations of missing climate variables are not considered. An example of this statement is the varying behavior of empirical formulae according to the type of climate considered (Jensen et al., 1990). Thus, there is little hope that a universal, accurate and robust empirical formula based on a limited set of weather variables will ever be proposed.

Choudhury (1997) proposed a method to assess $E_{0}$ by means of satellite data, such as remotely sensed solar radiation, air temperature (derived from infrared images and weather station measurements) and vapor pressure deficit. This method provides good evapotranspiration estimates for low-resolution applications such as worldwide scale and monthly time step. The accuracy is limited by the high uncertainties provided by satellite sensed vapor pressure estimations.

Several methods have been recently proposed to estimate solar radiation (Struzik, 2001). Amongst them, the Heliosat-2 method (Rigollier et al., 2004) has been proved to be reasonably reliable for estimating daily irradiation over Europe and Africa. This method has been used to elaborate a database, HelioClim-1, available at http://www.soda-is.org (Lefèvre et al., 2007).

Solar radiation strongly controls evaporation from the land surface. As small uncertainties in solar radiation may have considerable effect on the $E_{0}$ calculation (Llasat and Snyder, 1998) and as the variations in space of the radiation cannot be captured by pyranometers, which are in any case expensive and fragile devices, it can be assumed that remotely sensed solar irradiation should be useful for $E_{0}$ estimation.

In this paper, the relevance of remotely sensed solar radiation for computing $E_{0}$ at a daily time step is tested and discussed. First, a sensitivity analysis of the Penman-Monteith method to input variables for daily reference evapotranspiration calculation is performed. Then satellitesensed solar radiation data is compared to ground data and error propagations in several $E_{0}$ methods are evaluated. Finally, the accuracy of several $E_{0}$ methods based on solar radiation data are compared to the $E_{0}$ Hargreaves temperature method, to evaluate the benefits provided by the use of satellite-sensed solar radiation, for areas where air temperature is the only ground-measured available data.

\section{Methods}

\subsection{Study areas}

The study was performed in two regions of France (figure 1). One is located in the Southwest of France (hereafter referred to as SW). It is mostly flat and is characterized by a temperate climate under the influence of the Atlantic Ocean. Rainfalls range from $800 \mathrm{~mm}$ to $1800 \mathrm{~mm}$ per year; the average value for the area is $1000 \mathrm{~mm}$ per year. Summer is dry (mean of $60 \mathrm{~mm}$ per month), and autumn and winter are wet (approximately $100 \mathrm{~mm}$ per month). From 1971 
to 2000 , monthly means of temperatures varied from $5{ }^{\circ} \mathrm{C}$ in the winter to $20^{\circ} \mathrm{C}$ in the summer. The second area is the Southeast of France (hereafter referred to as SE). It exhibits marked orography due to the Southern Alps. The climate is Mediterranean, with hot and dry summers $(20 \mathrm{~mm}$ to $40 \mathrm{~mm}$ of rainfall per month and an average maximum temperature over $\left.30^{\circ} \mathrm{C}\right)$ and mild and wetter winters $(40 \mathrm{~mm}$ to $100 \mathrm{~mm}$ per month with mean temperature between $0{ }^{\circ} \mathrm{C}$ and $5{ }^{\circ} \mathrm{C}$ ).

\subsection{Data \\ 2.2.1 Ground station data}

Data was collected from 19 INRA-Agroclim weather stations. Eight are situated in Southwest area and 11 are located in Southeast area (table 1 and figure 1). All stations are Cimel ${ }^{\circledR}$ automatic weather stations, equipped with humidity and thermal sensors under a cylinder type disc shelter $(80 \mathrm{~mm} \times 150 \mathrm{~mm})$, cup anemometer and class 2 pyranometer. Minimum and maximum temperature, minimum and maximum relative humidity, solar irradiation and wind speed at 2 meters high at a daily time step were used. Average daily temperature is the mean of minimum and maximum daily temperatures values. The study was performed on a five year (2000-2004) data set.

\subsubsection{Satellite sensed solar radiation}

Remotely sensed solar irradiation was collected from the HelioClim-1 database available at http://www.soda-is.org. This database has been obtained by the application of the Heliosat-2 method to Meteosat satellite images. The Heliosat-2 method is based on the principle of the construction of a cloud index for each given pixel of satellite images (Cano et al., 1986 ; Rigollier et al., 2004). This index is obtained by calculating ground and cloud albedos from time-series of images acquired in a broadband channel spanning visible and near-infrared bands. A clear-sky index is then derived from the cloud index. Irradiation is obtained by multiplying this clear-sky index by the irradiation that should be observed under clear-sky conditions; the latter is estimated by means of the model of Rigollier et al. (2000). The precision of the method depends mostly on the cloud cover: relative uncertainties are lower during clear sky days (Rigollier et al., 2004 ; Lefèvre et al., 2007).

The HelioClim-1 database provides daily irradiation data for Europe and Africa. It has been constructed from a data set of reduced spatial resolution, called ISCCP-B2 data, that was created for the International Satellite Cloud Climatology Project (ISCCP) to better handle and exploit the wealth of information provided by the Meteosat series of satellites. The B2 data set is produced from Meteosat images by firstly performing a time sampling that reduces the frequency of observation to the standard meteorological synoptic 3-h intervals, starting at 0000 UTC. Secondly, the higher-resolution data in the visible channel are averaged to match the lower resolution of infrared channel data (i.e. an image of $2500 \times 2500$ pixels with a resolution of $5 \mathrm{~km}$ ). Finally, a spatial sampling is performed by taking 1 pixel over 6 in each direction (i.e. 1 pixel each $30 \mathrm{~km}$ ), starting with the south-easternmost pixel. For each remaining pixel, the irradiation was calculated every $3 \mathrm{~h}$ and integrated to provide daily irradiation. The HelioClim-1 database contains daily irradiation for these pixels (Lefevre et al., 2007). The irradiation data for any location are obtained by interpolating the daily values available at the nine closest pixels using inverse distance squared method (Lefèvre et al., 2002). Daily irradiation data were collected for the location of the 19 weather stations for the period 2000-2004.

\subsection{Reference evapotranspiration methods} 2.3.1 The FAO Penman-Monteith method 
The Penman-Monteith method combines energy balance and mass transfer concepts (Penman, 1948) with stomatal and surface resistance (Monteith, 1981).

Recently, the FAO proposed a standard parameterization of the Penman-Monteith method for estimating the evaporation from a well-irrigated, homogenous, $0.12 \mathrm{~m}$ grass cover considered as a "reference crop" (Allen et al., 1998). This method, hereafter referred as $P M$, is now used worldwide and the international agronomy community considers it as a standard. The FAO Penman-Monteith reference evapotranspiration $(\mathrm{mm})$ is calculated as follows:

$$
E_{P M}=\frac{0.408 \Delta\left(R_{n}\right)+\gamma \frac{900}{(T+273)} u_{2}\left(e_{s}-e_{a}\right)}{\Delta+\gamma\left(1+0.34 u_{2}\right)}
$$

where $\Delta$ is the slope of the saturation vapor pressure curve at air temperature $\left[\mathrm{kPa}{ }^{\circ} \mathrm{C}^{-1}\right], \gamma$ is the psychrometric constant $\left[\mathrm{kPa}^{\circ} \mathrm{C}^{-1}\right], T$ is the average air temperature $\left[{ }^{\circ} \mathrm{C}\right], u_{2}$ is the wind speed measured at $2 \mathrm{~m}$ above ground surface $\left[\mathrm{m} \mathrm{s}^{-1}\right], e_{s}$ and $e_{a}$ are the saturation and the actual vapor pressure $[\mathrm{kPa}]$, respectively, and $R_{n}$ is the net radiation $\left[\mathrm{MJ} \mathrm{m}^{-2}\right]$, calculated as follows :

$$
R_{n}=R_{n s}-R_{n l}
$$

where $R_{n s}$ is the net shortwave radiation [ $\left.\mathrm{MJ} \mathrm{m}^{-2}\right]$ given by :

$$
R_{n s}=(1-a) R_{s}
$$

and $R_{n l}$ is the net longwave radiation [MJ $\mathrm{m}^{-2}$ ] given by :

$$
R_{n l}=\sigma\left[\frac{T_{\max , K}^{4}+T_{\min , K}^{4}}{2}\right]\left(0.34-0.14 \sqrt{e_{a}}\right)\left(1.35 \frac{R_{s}}{R_{s o}}-0.35\right)
$$

where $R_{s}$ is the global solar radiation $\left[\mathrm{MJ} \mathrm{m}^{-2}\right], a$ is the albedo of the hypothetical grass reference crop, set to $0.23, T_{\max , K}$ and $T_{\min , K}$ are the maximum and minimum air temperature $[\mathrm{K}]$, respectively, and $R_{s o}$ is the clear-sky solar radiation $\left[\mathrm{MJ} \mathrm{m}^{-2}\right]$, given by :

$$
R_{s o}=\left(0.75+2 z 10^{-5}\right) R_{a}
$$

where $z$ is the station elevation above sea level [m] and $R_{a}$ is the extraterrestrial radiation $\left[\mathrm{MJ} \mathrm{m}^{-2}\right]$. Undefined components used in equations (2), (3), (4) and (5) have the same signification and units as in equation (1).

The actual vapor pressure [kPa], used in equations (1) and (4) is calculated as follows:

$$
e_{a}=\frac{e^{\mathrm{o}}\left(T_{\min }\right) \frac{R H_{\max }}{100}+e^{\circ}\left(T_{\max }\right) \frac{R H_{\min }}{100}}{2}
$$

where $\mathrm{e}^{\circ}\left(T_{\min }\right)$ and $\mathrm{e}^{\circ}\left(T_{\max }\right)$ are the saturation vapor pressure at minimum and maximum air temperature [kPa], respectively, $R H_{\min }$ is the minimum relative humidity and $R H_{\max }$ is the maximum relative humidity.

The slope of saturation vapor pressure curve at air temperature is given by :

$$
\Delta=\frac{4098\left[e^{\circ}(T)\right]}{(T+237.2)^{2}}
$$

where $\mathrm{e}^{\circ}(T)$ is the saturation vapor pressure at average air temperature and $T$ as the same signification and units as in equation (1).

$P M$ or other Penman-Monteith versions have been proved to be among the most precise and accurate models for daily reference evapotranspiration prediction under different climatic conditions when compared to lysimetric measurements (Allen et al., 1989; Hargreaves and Allen, 2003 ; Garcia et al., 2004 ; Pereira, 2004; Pereira and Pruitt, 2004).

In this paper, $E_{P M}$ is considered as the reference value against which other empirical methods will be compared. This choice is motivated by the fact that most of the applications based upon reference evapotranspiration, such as irrigation schemes, hydrological studies or water balance modelling, use calculated $E_{0}$ rather than lysimetric measurements. 


\subsubsection{Empirical methods}

In this study, radiation methods, i.e. empirical methods that calculate $E_{0}$ with air temperature and solar radiation, are singled out, in order to test the relevance of using remotely sensed solar radiation for $E_{0}$ estimates.

Three radiation methods and one temperature method were compared to $P M$. Hargreaves radiation method (hereafter referred as to $H R$, Hargreaves and Samani, 1982) was established in 1975 from a regression with lysimeter data collected at Davis (California, USA) and the product of temperature and solar radiation, for a five day time step. The following prediction equation was then proposed:

$$
E_{H R}=0.0135 \frac{R_{s}}{\lambda}(T+17.8)
$$

where $\lambda$ is the latent heat of vaporization $=2.45 \mathrm{MJ} \mathrm{kg}^{-1}$ at $20^{\circ} \mathrm{C}$ (as $\lambda$ is very stable, this value was used in the current study), and other components having the same signification and units as in equations (1) and (3). Hargreaves radiation method has seldom been tested, despite encouraging results (Hargreaves and Allen, 2003). As solar radiation has rarely been available, Hargreaves proposed a modified version of this method, so that reference evapotranspiration could be estimated with minimum and maximum air temperature only (Hargreaves et al., 1985). This method is known as the 1985 Hargreaves temperature method (hereafter referred to as HT):

$$
E_{H T}=0.0023 \frac{R_{a}}{\lambda}(T+17.8) \sqrt{\left(T_{\max }-T_{\min }\right)}
$$

where $T_{\min }$ and $T_{\max }$ are the minimum and the maximum air temperature, respectively $\left[{ }^{\circ} \mathrm{C}\right]$. and undefined components having the same signification and units as in equations (1), (5) and (8). Local calibrations of the empirical coefficient (0.0023), based upon regional wind speed and air temperature, were recently proposed (Gavilan et al., 2006).

The Turc radiation method (hereafter referred to as $T U$; Turc, 1961), initially developed for 10-day periods, provides good results for a humid environment (Jensen et al., 1990).

Reference evapotranspiration is calculated as follows:

$$
E_{T U}=0.013\left(23.88 R_{s}+50\right)\left(\frac{T}{T+15}\right)
$$

where $R_{s}$ and $T$ have the same signification and units as in equations (1) and (3). The Priestley-Taylor method (hereafter referred as $P T$, Priestley and Taylor, 1972), unlike radiation methods presented above, is mostly based on physical principles. The $P T$ method is derived from energy balance concepts and the hypothesis that (at least for short vegetation) fluxes over land are mostly governed by radiative rather than advected energy. Thus, $E_{0}$ is given by:

$$
E_{P T}=\alpha \frac{\Delta}{\Delta+\gamma} R_{n}
$$

where $\alpha$ is an empirical and unitless coefficient, set to 1.26 , and $R_{n}, \Delta$ and $\gamma$ have the same signification and units as in equation (1). To avoid the use of minimum and maximum relative humidity for $E_{P T}$ calculation ( $E_{P T}$ is calculated with air temperature and solar radiation only), the actual vapour pressure $e_{a}$, required for $R_{n}$ calculation (equation (4)) is estimated from minimum air temperature only:

$$
e_{a}=e^{\circ}\left(T_{\min }\right)=0.611 \exp \left[\frac{17.27 T_{\min }}{T_{\min }+237.3}\right]
$$

where $e_{a}$ and $T_{\min }$ have the same significance and units as in equations (6) and (9). 
Equation (12) follows the recommendations in Allen et al. (1998) to compute $e_{a}$ when relative humidity is missing. $P T$ method has been used and tested in many studies, and has shown to be reliable in humid climate conditions for evaporation (Xu and Singh, 2000) and reference evapotranspiration (Jensen et al., 1990) estimations. Local adjustments of $\alpha$ are necessary in numerous cases (Xu and Singh, 2002; Bois et al., 2005; Fisher et al., 2005), and a calculation method for $\alpha$ based on surface and aerodynamic resistance parameters was proposed by Pereira (2004). A recalibration of $\alpha$ to increase the precision of $P T$ estimates, is discussed in the results section, but the results presented in this paper focus on the $P T$ method with $\alpha$ set to 1.26 , as recalibration of empirical formulae is not the main objective of the present sutdy.

\subsection{Sensitivity analysis}

\subsubsection{The Sobol' method}

To estimate the relative participation of climate variables to $P M$ model output, a sensitivity analysis was performed. There are several approaches available for sensitivity analysis studies (see Frey and Patil, 2002 or Saltelli et al., 2006 for reviews). For the present work, the Sobol' based variance method was used (Sobol', 1993). This method allows evaluating the sensitivity of a model to interaction between input variables. It consists of numerous simulations of the models using two independent samples of $N$ repetitions (rows) and $k$ input variables (columns), retrieved from existing data or randomly generated data from the probability distribution function of each $k$ input variable. One or several variables in the first sample are substituted by the same variable(s) taken from the second sample. For each of the $\left(2^{k}-1\right)$ possible combinations of variable substitutions between the two samples, $N$ runs of the model are computed. The sensitivity of the model to input variables is based on so-called sensitivity or Sobol' indices, which are calculated on the principle of the decomposition of the total variance $V$ of the model output, in response to individual or simultaneous variations of the $k$ model inputs:

$$
V=\sum_{i} V_{i}+\sum_{i<j} V_{i j}+\sum_{i<j<m} V_{i j m}+\cdots+V_{1,2, \ldots, k}
$$

Where $V_{i}$ is the model output variance in response to variation of the $i$ th input variable, $V_{i j}$ is the model output variance in response to the simultaneous variation of the $i$ th and the $j$ th model input, and so-on. Then, sensitivity indices are calculated as follows:

$$
\begin{gathered}
S_{i}=\frac{V_{i}}{V} \\
S_{T i}=\frac{V_{i}+\sum_{j} V_{i j}+\sum_{j<m} V_{i j m}+\ldots+V_{i, j \ldots, k}}{V}
\end{gathered}
$$

where $j$ and $m$ are the $j$ th and the $m$ th model input variables, and $i \neq j \neq m . S_{i}$ is called the first order sensitivity index. It measures the sensitivity of the model to the input variable $X_{i}$. $S_{T i}$ is called the total sensitivity index. It measures the impact of variations of the $i$ th model input on the model output, including all the possible interactions with other input variations. For more details about the Sobol' method, see Saltelli (2002).

\subsubsection{Sensitivity analysis of $\mathrm{PM}$ reference evapotranspiration formula}

A major constraint, when trying to perform a sensitivity analysis, is the interdependency of input variables. Considering the Penman-Monteith FAO-56 formula, required input data are minimum and maximum air temperature, minimum and maximum relative humidity, solar radiation and wind speed. Minimum and maximum air temperature and relative humidity, if picked randomly in a data set, will lead to nonsense computations, i.e. having a minimum air 
temperature or relative humidity value higher than the maximum. To solve this problem average air temperature and relative humidity and their daily amplitudes were calculated prior to elaborating the two random data sets required for Sobol' method:

$$
T=\frac{T_{\min }+T_{\max }}{2} ; R H=\frac{R H_{\min }+R H_{\max }}{2}
$$

and

$$
\Delta T=T_{\max }-T_{\min } ; \Delta R H=R H_{\max }-R H_{\text {min }}
$$

where $T$ and $R H$ are the daily average air temperature $\left[{ }^{\circ} \mathrm{C}\right]$ and the daily average relative humidity [\%], $\Delta T\left[{ }^{\circ} \mathrm{C}\right]$ and $\Delta R H[\%]$ are their daily amplitude, and $T_{\min }, T_{\max }, R H_{\min }$ and $R H_{\max }$ having the signification and units as in equations (6) and (9). Once random samples are created, $T, R H, \Delta T$ and $\Delta R H$ are used to retrieve minimum and maximum air temperature and relative humidity daily values, inverting the equations (16), (17), (18) and (19). A major requirement of sensitivity analysis is the choice of the input data set. The aim of the present SA is to retrieve the climate variables which $P M$ model is most sensitive to, according to different climatic conditions, i.e. Oceanic and Mediterranean climates. It is assumed that the climate stations within both study areas ( 8 for SW and 11 for SE) provide a good sample of the spatial variation of climatic conditions. To take into account the variability of climate during the year, sensitivity analyses were performed for each month. That is, the input data set for Sobol' SA is generated for a given month, according to the probability distribution function (PDF) of each input data, recorded at the stations of a given study area (SW or SE). For each month and each area, Sobol' SA was assessed as follows (figure 2): (a) empirical PDF of each input variable were fitted to empirical distributions of the data sets recorded at the (8 or 11) climate stations area during 2000 to 2004, using a Gaussian Kernel fitting function with R statistical software (R Development Core Team, 2007) ; (b) Two samples were generated by quasi-random sampling with 10000 repetitions ; (c) Several model outputs and variance decomposition were computed using Sobol' algorithm of the package sensitivity of R statistical software ; (d) First order and total sensitivity indexes and their monthly evolution were then compared. Note that for step (b), one could propose the use of the original data record rather than random sample generations. However, the number of available data for each month was not sufficient for the statistical robustness of the analysis.

\subsection{Statistical indices used for satellite sensed solar radiation and empirical $\mathrm{E}_{0}$ formulae evaluations}

The reference data used to evaluate satellite-sensed solar radiation were pyranometer records at ground level. For evapotranspiration, $P M$ (equation (1)), using pyranometer records, was used as a reference data for empirical formulae evaluation. For each day $i$, the difference between reference and estimated data was calculated as follows :

$$
D_{i}=\text { Est }_{i}-\text { Ref }_{i}
$$

where $D$ is the difference (or "error") [mm], Est $t_{i}$ is the satellite-sensed solar radiation or the $E_{0}$ estimated with an empirical method and $\operatorname{Ref}_{i}$ is the reference data. The units are $\mathrm{MJ} \mathrm{m}^{-2}$ or $\mathrm{mm}$ according to the type of data evaluated.

The accuracy of each method is given by the bias (or mean error):

$$
\text { bias }=\frac{1}{n} \sum_{i=1}^{n} D_{i}
$$

The unit of bias is $\mathrm{mm}$ or $\mathrm{MJ} \mathrm{m} \mathrm{m}^{-2}$, according to the type of data evaluated, and $n$ is the number of days.

The precision is given by the root mean squared error (RMSE): 


$$
R M S E=\sqrt{\frac{1}{n} \sum_{i=1}^{n} D_{i}^{2}}
$$

Errors populations were also analyzed by means of coefficient of determination $\left(\mathrm{R}^{2}\right)$.

\section{Results and discussion}

\subsection{Sensitivity analysis of PM formula}

Sensitivity of $\mathrm{E}_{0}$ computation using PM method in Southwest area (Oceanic climate). The results of monthly sensitivity analyses computed using Southwest area data show clear seasonal trends (figure 3A). During the winter period (from November to February), wind speed is the main source of variation in $E_{0}$ values calculated using $P M$ method (e.g. $38 \%$ of $E_{0}$ total variance in January, table 2$)$. Then come relative humidity and air temperature (32\% and $17 \%$ of $E_{0}$ total variance in January, respectively). Solar radiation, daily amplitude of air temperature and daily amplitude of relative humidity have little impact on evapotranspiration process during winter. This trend changes during March and October. From April to September, $E_{0}$ is mostly sensitive to solar radiation (up to $74 \%$ of $E_{0}$ total variance in May, and $70 \%$ in July). From May to July, $P M$ formula is not very sensitive to $R H, U_{2}, \Delta R H$ and $\Delta T$. Mean daily air temperature participate from $11 \%$ to $15 \%$ of $E_{0}$ variance, from May to September. Total sensitivity indices show that, when added to other variables variations, air temperature has a greater impact on $E_{0}$ variability during summer, and wind speed has a greater impact during winter (figure 3B). Sensitivity of $\mathrm{E}_{0}$ computation using PM method in Southeast area (Mediterranean climate). The sensitivity of $P M$ formula to climate input variables in Mediterranean climate conditions is very close to the one observed for Oceanic climate. Wind speed as a major impact on $E_{0}$ calculation during winter and solar radiation is clearly the most influent variable during summer (figures $3 \mathrm{C}$ and $3 \mathrm{D}$, table 2).

The present analysis highlights the great sensitivity of this Penman-Monteith formula to solar radiation during summer period, when $E_{0}$ reaches its highest values, and when its calculation is critical for irrigation process and ecological modelling. These results were obtained for Mediterranean and Oceanic climate, at medium latitudes. They are consistent with former uncertainty and sensitivity analyses performed in Mediterranean climate (Llasat and Snyder, 1998 ; Rana and Katerji, 1998). A recent work published by Gong et al. (2006) on a large range of climatic conditions in Southern China leads to similar results, except for relative humidity which had a greater impact on $E_{0}$ during winter than it has been shown in the present study.

Considering the results of Penman-Monteith sensitivity to solar radiation, it seems reasonable to evaluate the benefits of satellite sensed solar radiation to $E_{0}$ calculation when no solar radiation ground records are available. This point is studied and discussed in the next section.

\subsection{Remotely sensed solar radiation performances}

Table 3 shows the annual error statistics of solar radiation and $E_{0}$ data calculated with HelioClim-1 data instead of pyranometer radiation data. HelioClim-1 underestimates daily irradiation (figures 4A and 4D). The bias is twice as important for Southwest area ($\left.1.87 \mathrm{MJ} \mathrm{m}^{-2}\right)$ as it is for Southeast area $\left(-1.07 \mathrm{MJ} \mathrm{m}^{-2}\right)$. RMSE is also higher for SW $(20 \%$ of the annual solar irradiation) than for SE (14\%). Although the uncertainty, in absolute value, is larger during summer period (Figure 5A), the RMSE are 15\% (SW) and 10\% (SE) of $R_{S}$ pyranometer value in July, whereas they reach $26 \%$ (SW) and $18 \%$ (SE) in January, as irradiation is larger during summer. These errors are consistent with those observed in Northern Europe, during former evaluations of HelioClim-1 database (Lefèvre et al., 2007). When no pyranometer data is 
available, daily satellite sensed solar radiation should be preferred to temperature-based estimations: for both areas, daily irradiation RMSE are 3 to 4 times smaller than those obtained by Hunt et al. (2000) in Ontario (Canada), with empirical formulae based on air temperature. Moreover, HelioClim-1 irradiation may be as precise as pyranometer measurements where weather stations are not steadily maintained or not equipped with accurate devices: uncertainty reported varies from 5 to $25 \%$, according to the class of material and the metrology experts (Llasat and Snyder, 1998 ; Droogers and Allen, 2002). There are several sources of uncertainties when comparing satellite data to very local measurements, such as weather station records. This point has been widely discussed by Zelenka et al. (1999). First, it is difficult to compare pixel data, corresponding to a surface, with a discrete measurement, such as pyranometer weather station records. Another category of uncertainties comes from the spatial (1 pixel each 30 kilometer) and temporal ( 3 hours) resolutions of the initial data set used to create the HelioClim-1 database. In addition, the spatial interpolation method generates its intrinsic uncertainties. The Heliosat-2 method itself, used to elaborate the HelioClim-1 database, also participate to uncertainties of satellite sensed irradiation data (e.g. the algorithm limits). The uncertainties inherent to the ISCCP-B2 data set could be avoided by applying the Heliosat- 2 method to each original Meteosat pixel and for every hour. The HelioClim-2 database was created in that respect but begins only in 2004 and could not be used in this study.

\subsection{Propagation of satellite sensed solar radiation errors in $\mathrm{E}_{0}$ formulae} Replacing pyranometer measurement by Heliosat-2 estimations (i.e. HelioClim-1 data) induces little error for reference evapotranspiration calculation using the Penman-Monteith model (table 3). Estimation errors are higher for middle range $E_{0}$ values (figure $4 \mathrm{~B}$ and $4 \mathrm{E}$ ). This could be explained by the fact that most of the errors occur for partially cloudy days, due to uncertainties in retrieving daily solar radiation with Heliosat-2 method for this type of weather (Rigollier et al., 2004). In both areas, $E_{P M}$ is slightly underestimated. For SW, biases vary from $-0.34 \mathrm{~mm}$ to $0.01 \mathrm{~mm}$, according to the season (figure $5 \mathrm{~B}$ ). The annual RMSE value remains low ( $11 \%$ of $E_{0}$ mean value). In $\mathrm{SE}$ area, $E_{P M}$ bias is negligible $(-0.20 \mathrm{~mm}$ to $0.01 \mathrm{~mm}$, figure 5C). Relative RMSE in SE is $7 \%$ of $E_{0}$ mean value, which is lower than in SW. Heliosat-2 method is more successful for clear sky days, which could explain the difference between the two regions, as clear sky situations occur more frequently in SE than SW. Relative errors of $E_{P M}$ calculated with HelioClim-1 are lower during summer ( $9 \%$ for SW and 5\% for SE, in July). Again, the better performance of Heliosat-2 method for clear sky days could explain this seasonal trend, as clear sky situations are more numerous during summer than during the other seasons. Yet, higher relative errors could have been expected: sensitivity analyses have shown that solar radiation has the greatest impact on $P M$ model during summer (i.e. when evapotranspiration reaches its maximum) in Oceanic or Mediterranean climates (see section 3.1).

Errors are higher when pyranometer data is replaced by HelioClim-1 data in radiation methods, i.e. $H R, T U$ and $P T$ (figure $4 \mathrm{C}$ and $4 \mathrm{~F}$, table 3 ). Biases are mostly negative. Sensitivity to solar radiation errors is higher for radiation methods than for $P M$ because radiation methods do not include advective effects on the evapotranspiration process and thus are mainly governed by radiative transfers. The largest error propagation can be observed for the Hargreaves radiation method (table 3, figures 5B and 5C).

\subsection{Empirical formulae performance}

Daily $E_{0}$ values of 4 empirical methods were compared to reference evapotranspiration computed with $P M$. HelioClim-1 solar radiation was used for radiation methods, whereas 
pyranometer data was used for $P M$, as it was considered here as the "control" method. Data sources used for $E_{0}$ calculations are shown in table 4.

In both areas, Hargreaves temperature method (HT) gave the highest uncertainties for the annual period (table 5). During summer, formulae using satellite-sensed solar radiation improve considerably $E_{0}$ estimation compared to $H T$ estimates based solely on local air temperature. Figures $6 \mathrm{~A}$ and $6 \mathrm{~B}$ show an obvious seasonal trend of $H T$ errors, which is related to the variations in sensitivity of $E_{0}$ to the different input variables of $P M$ : during summer, when $E_{0}$ is mainly governed by solar radiation, estimates based upon air temperature only are thus less accurate.

Evapotranspiration calculated with satellite-sensed solar radiation is mainly underestimated. For both climates, all radiation methods show biases similar to those induced by replacement of pyranometer data by satellite-sensed solar radiation (between $-0.4 \mathrm{~mm}$ and $-0.2 \mathrm{~mm}$, table 3 and 5): this suggests that the underestimation observed is mainly due to the propagation of HelioClim-1 data bias within radiation methods, rather than wrong calibration of empirical coefficients used in these formulae.

In the Southwest area, $P T$ data is strongly correlated to $P M$ data $\left(\mathrm{R}^{2}=0.938\right.$, table 5). It is also the formula providing the lowest $E_{0}$ RMSE during summer and for the whole year (figure 6A). Turc and Hargreaves radiation method performances are almost the same. The performance of $T U$ is slightly better than other formulae from September to November. It has been shown in former studies that the Turc method provides good results in humid environment (Jensen et al., 1990 ; Turc, 1961), whereas Hargreaves radiation method has been established from arid or semi-arid climate data analysis (Hargreaves and Allen, 2003). These differences between those two formulae did not emerge from the current study, in Southwest oceanic climate. Hargreaves temperature method provided the lowest RMSE and the lowest bias (in absolute value), from January to April. However, this temperature-based method was the least accurate method for SW, when considering summer and annual periods (RMSE $=0.67 \mathrm{~mm}, \mathrm{R}^{2}=0.894$, for the whole year). $H T$ overestimated $E_{0}$ (a mean error of $0.32 \mathrm{~mm})$.

For the Southeast area, all empirical formulae showed poorer performances when compared to the Southwest region (figure 6B). The higher wind speed and the lower relative humidity in SW throughout the year might explain these differences (results not shown). $H R$ provided the most precise $E_{0}$ estimates for the whole year $\left(\mathrm{RMSE}=0.77 \mathrm{~mm}\right.$, i.e. $25 \%$ of $E_{0}$ mean annual value). The best correlation with $P M$ values is provided by $P T$. The Priestley-Taylor formula performed better than every other formula during summer, but showed considerable bias and RMSE during winter. The lowest bias (in absolute value) is provided by $H T$, which showed in contrast high RMSE $(0.96 \mathrm{~mm}$, i.e. $31 \%$ of the annual mean). These results suggest that using satellite sensed-solar radiation within empirical formulae improve the accuracy of $E_{0}$ estimates during summer and for the whole year, although reference evapotranspiration remains underestimated in most cases.

\section{Conclusions}

The present work focused on the role of solar radiation data in reference evapotranspiration calculation at daily time steps. A sensitivity analysis of the Penman-Monteith model showed that solar radiation strongly governs reference evapotranspiration during summer, for Oceanic and Mediterranean climates at medium latitude. The use of satellite-sensed solar radiation taken from HelioClim-1 database for $E_{0}$ calculation was evaluated. It was shown that HelioClim-1 data underestimates solar radiation at daily time step, for Oceanic and Mediterranean climates in France. The RMSE ranges from 14 to $20 \%$ of the annual solar radiation. The error propagation is considerable in radiation-based methods, as these equations are linearly linked to solar radiation input. 
472 Amongst the numerous studies concerning reference evapotranspiration estimates with 473 limited climatic data, few considered daily time step. When temperature data is the sole 474 climate variable available, Hargreaves temperature method is often used or recommended and provides relative RMSE ranging from $20 \%$ to $30 \%$ of the mean annual value, depending on the type of climate (Droogers and Allen, 2002; Hargreaves and Allen, 2003). In the present work, we found that using satellite sensed global radiation via $P T$ or $H R$ methods improves $E_{0}$ estimates, compared to Hargreaves temperature method. With these empirical solar radiationbased methods, relative annual RMSE ranges from $22 \%$ to $28 \%$, according to the method and the type of climate, humid-Oceanic or semi-arid-Mediterranean. Hargreaves temperature method, however, produced annual RMSE of $28 \%$ of the annual mean for Oceanic climate and $31 \%$ for Mediterranean climate. The difference in precision between radiation and Hargreaves temperature method reaches its maximum during summer, when the $E_{0}$ process is mainly governed by solar radiation. In contrast, $H T$ showed smaller uncertainties than radiation methods with HelioClim-1 data during winter.

These results suggest that during summer, using empirical radiation methods with satellite sensed solar radiation from the HelioClim-1 database to estimate $E_{0}$ should be preferred to $H T$, when air temperature is the only available record at weather stations.

These observations need to be verified in other climatic conditions, and especially in arid climates, where $E_{0}$ estimation is crucial for water management. This could be easily done using HelioClim-1 database, as it provides data for a large surface of the globe, i.e. from Northern Europe to South-Africa.

\section{Acknowledgements}

The authors would like to thank the Conseil Interprofessionnel des Vins de Bordeaux for their financial and technical support. Thanks to the Center for Energy and Processes (Centre Energétique et Procédés, Sophia-Antipolis, France) for providing HelioClim-1 data. 


\section{References}

Allen, R.G., Jensen, M.E., Wright, J.L. and Burman, R.D., 1989. Operational estimates of reference evapotranspiration. Agronomy Journal, 81(4): 650-662.

Allen, R.G., Pereira, L.S., Raes, D. and Smith, M., 1998. Crop evapotranspiration: guidelines for computing crop water requirements. FAO Irrigation and Drainage Paper. Food and Agriculture Organization (FAO), Rome Italy, $300 \mathrm{pp}$.

Bois, B., Pieri, P., Van Leeuwen, C. and Gaudillere, J.P., 2005. Sensitivity analysis of the Penman-Monteith evapotranspiration formula and comparison of empirical methods used in viticulture soil water balance, XIV International GESCO Viticulture Congress, Geisenheim, Germany, 23-27 August, 2005.

Brisson, N., Seguin, B. and Bertuzzi, P., 1992. Agrometeorological soil water balance for crop simulation models. Agricultural and Forest Meteorology, 59(3-4): 267-287.

Cano, D., Monget, J.-M., Albuisson, M., Guillard, H., Regas, N. and Wald L., 1986. A method for the determination of the global solar radiation from meteorological satellites data. Solar Energy, 37(1): 31-39.

Cukier, R.I., Levine, H.B. and Shuler, K.E., 1978. Nonlinear sensitivity analysis of multiparameter model systems. Journal of Computational Physics, 26(1): 1-42.

Choudhury, B.J., 1997. Global pattern of potential evaporation calculated from the PenmanMonteith equation using satellite and assimilated data. Remote Sensing of Environment, 61(1): 64-81.

Droogers, P. and Allen, R.G., 2002. Estimating reference evapotranspiration under inaccurate data conditions. Irrigation and Drainage Systems, 16(1): 33-45.

Fisher, J.B., DeBiase, T.A., Qi, Y., Xu, M. and Goldstein, A.H., 2005. Evapotranspiration models compared on a Sierra Nevada forest ecosystem. Environmental Modelling \& Software, 20(6): 783-796.

Frey, H.C. and Patil, S.R., 2002. Identification and review of sensitivity analysis methods. Risk Analysis, 22(3): 553-578.

Garcia, M., Raes, D., Allen, R. and Herbas, C., 2004. Dynamics of reference evapotranspiration in the Bolivian highlands (Altiplano). Agricultural and Forest Meteorology, 125(1/2): 67-82.

Gavilan, P., Lorite, I.J., Tornero, S. and Berengena, J., 2006. Regional calibration of Hargreaves equation for estimating reference ET in a semiarid environment. Agricultural Water Management, 81(3): 257-281.

Gong, L., Xu, C.-y., Chen, D., Halldin, S. and Chen, Y.D., 2006. Sensitivity of the PenmanMonteith reference evapotranspiration to key climatic variables in the Changjiang (Yangtze River) basin. Journal of Hydrology, 329(3/4): 620-629.

Guyot, G., 1997. Climatologie de l'environnement. De la plante aux ecosystèmes. Masson, Paris, 505 pp.

Hargreaves, G.H. and Allen, R.G., 2003. History and Evaluation of Hargreaves Evapotranspiration Equation. Journal of Irrigation and Drainage Engineering, 129(1): 53-63.

Hargreaves, G.H. and Samani, Z.A., 1982. Estimating Potential Evapotranspiration. Journal of the Irrigation and Drainage Division, 108: 223-230.

Hargreaves, G.L., Hargreaves, G.H. and Riley, J.P., 1985. Agricultural benefits for Senegal River Basin. Journal of Irrigation and Drainage Engineering, 111: 111-124.

Hunt, L. A., Kuchar, L. and Swanton, C. J., 1998. Estimation of solar radiation for use in crop modelling. Agricultural and Forest Meteorology 91 (3/4): 293-300.

Jensen, M.E., Burman, R.D. and Allen, R.G., 1990. Evapotranspiration and Irrigation Water Requirements. ASCE Manuals and Reports on Engineerings Practices, 70. American Society of Civil Engineers, New York, 360 pp. 
Lebon, E., Dumas, V., Pieri, P. and Schultz, H.R., 2003. Modelling the seasonal dynamics of the soil water balance of vineyards. Functional Plant Biology, 30(6): 699-710.

Lefèvre, M., Remund, J., Albuisson, M. and Wald, L., 2002. Study of effective distances for interpolation schemes in meteorology. Geophysical Research Abstracts, 4, April 2002, EGS02-A-03429, European Geophysical Society.

Lefevre, M., Wald, L. and Diabate, L., 2007. Using reduced data sets ISCCP-B2 from the Meteosat satellites to assess surface solar irradiance. Solar Energy, 81(2): 240-253.

Llasat, M.C. and Snyder, R.L., 1998. Data error effects on net radiation and evapotranspiration estimation. Agricultural and Forest Meteorology, 91(3/4): 209-221.

Monteith, J.L., 1981. Evaporation and surface temperature. Quaterly Journal Of The Royal Meteorogical Society, 107(451): 1-27.

Penman, H.L., 1948. Natural evaporation from open water, bare soil and grass. Proceedings of the Royal Society of London, A193: 120-146.

Pereira, A.R., 2004. The Priestley-Taylor parameter and the decoupling factor for estimating reference evapotranspiration. Agricultural and Forest Meteorology, 125(3/4): 305-313.

Pereira, A.R. and Pruitt, W.O., 2004. Adaptation of the Thornthwaite scheme for estimating daily reference evapotranspiration. Agricultural Water Management, 66(3): 251-257.

Popova, Z., Kercheva, M. and Pereira, L.S., 2005. Validation of the FAO methodology for computing ET0 with limited data, ICID 21st European Regional Conference, Frankfurt and Slubice, 13pp.

Priestley, C.H.B. and Taylor, R.J., 1972. On assessment of surface heat flux and evaporation using large-scale parameters. Monthly Weather Review, 100: 81-92.

R Development Core Team, 2007. R: A Language and Environment for Statistical Computing. R Foundation for Statistical Computing, Vienna, Austria.

Rigollier, C., Bauer, O. and Wald, L., 2000. On the clear sky model of the ESRA - European Solar Radiation Atlas - With respect to the Heliosat method. Solar Energy, 68(1): 3348.

Rigollier, C., Lefevre, M. and Wald, L., 2004. The method Heliosat-2 for deriving shortwave solar radiation from satellite images. Solar Energy, 77(2): 159-169.

Rana, G. and Katerji, N., 1998. A Measurement Based Sensitivity Analysis of the PenmanMonteith Actual Evapotranspiration Model for Crops of Different Height and in Contrasting Water Status. Theoretical and Applied Climatology, 60(1): 141-149.

Saltelli, A., 2002. Making best use of model evaluations to compute sensitivity indices. Computer Physics Communications, 145(2): 280-297.

Saltelli, A., Ratto, M., Tarantola, S. and Campolongo, F., 2006. Sensitivity analysis practices: Strategies for model-based inference. Reliability Engineering \& System Safety, 91(1011): 1109-1125.

Sobol', I.M., 1993. Sensitivity analysis for non-linear mathematical model. Mathematical Modeling and Computational Experiment, 1: 407-414.

Struzik, P., 2001. Spatialisation of Solar Radiation - draft report on possibilities and limitations, COST action 718, 3rd Management committee and Working Group Meeting, Budapest, Hungary, pp. 12.

Turc, L., 1961. Evaluation des besoins en eau d'irrigation, évapotranspiration potentielle. Annales Agronomiques, 12(1): 13-49.

Xu, C.Y. and Singh, V.P., 2000. Evaluation and generalization of radiation-based methods for calculating evaporation. Hydrological Processes, 14: 339-349.

$\mathrm{Xu}$, C.Y. and Singh, V.P., 2002. Cross comparison of empirical equations for calculating potential evapotranspiration with data from Switzerland. Water Resources Management, 16(3): 197-219 
Zelenka, A., Perez, R., Seals, R. and Renne, D., 1999. Effective accuracy of satellite-derived hourly irradiances. Theoretical and Applied Climatology, 62(3/4): 199-207.

599

600

SoDa web site: http://www.soda-is.org

601 


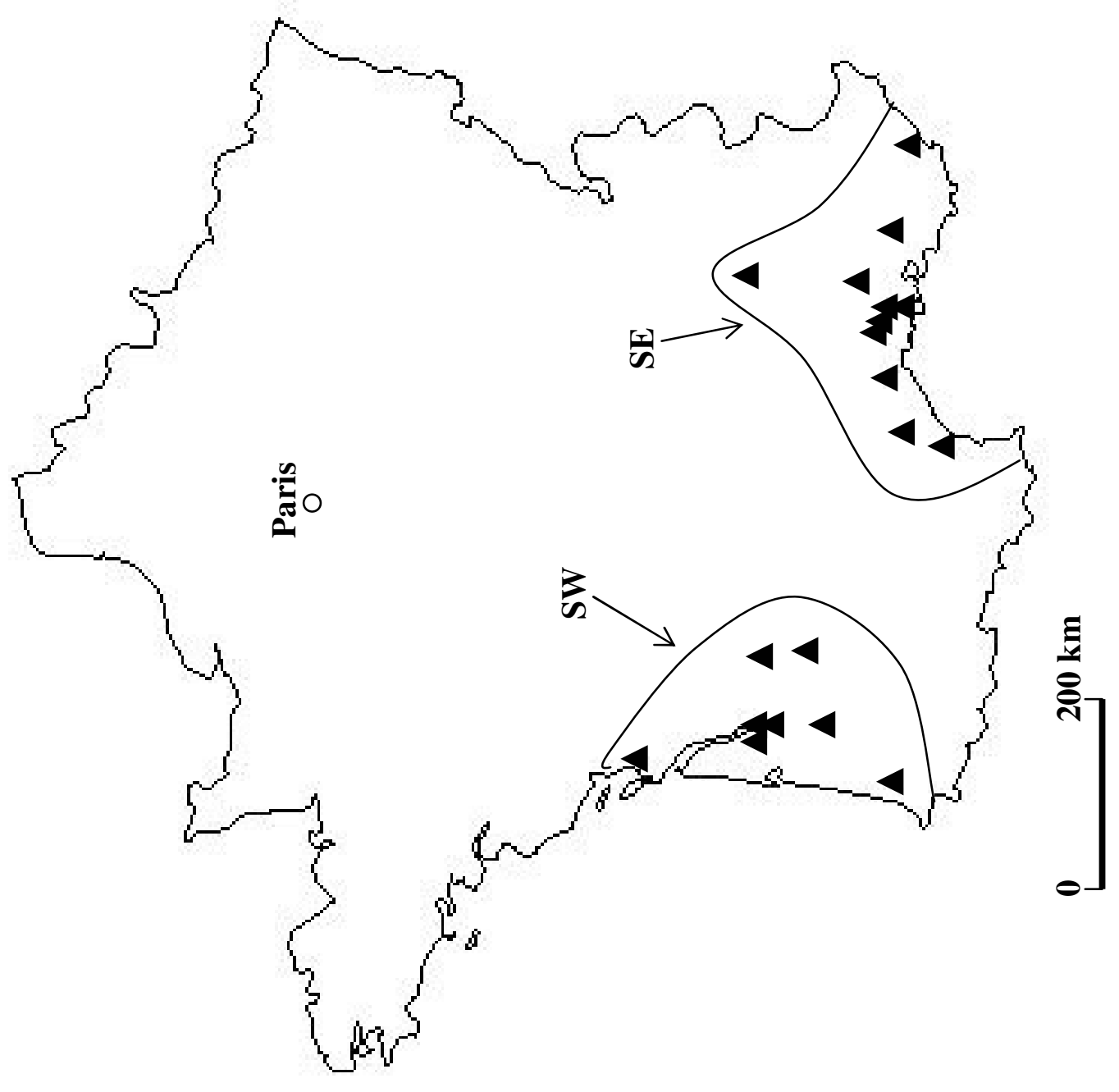




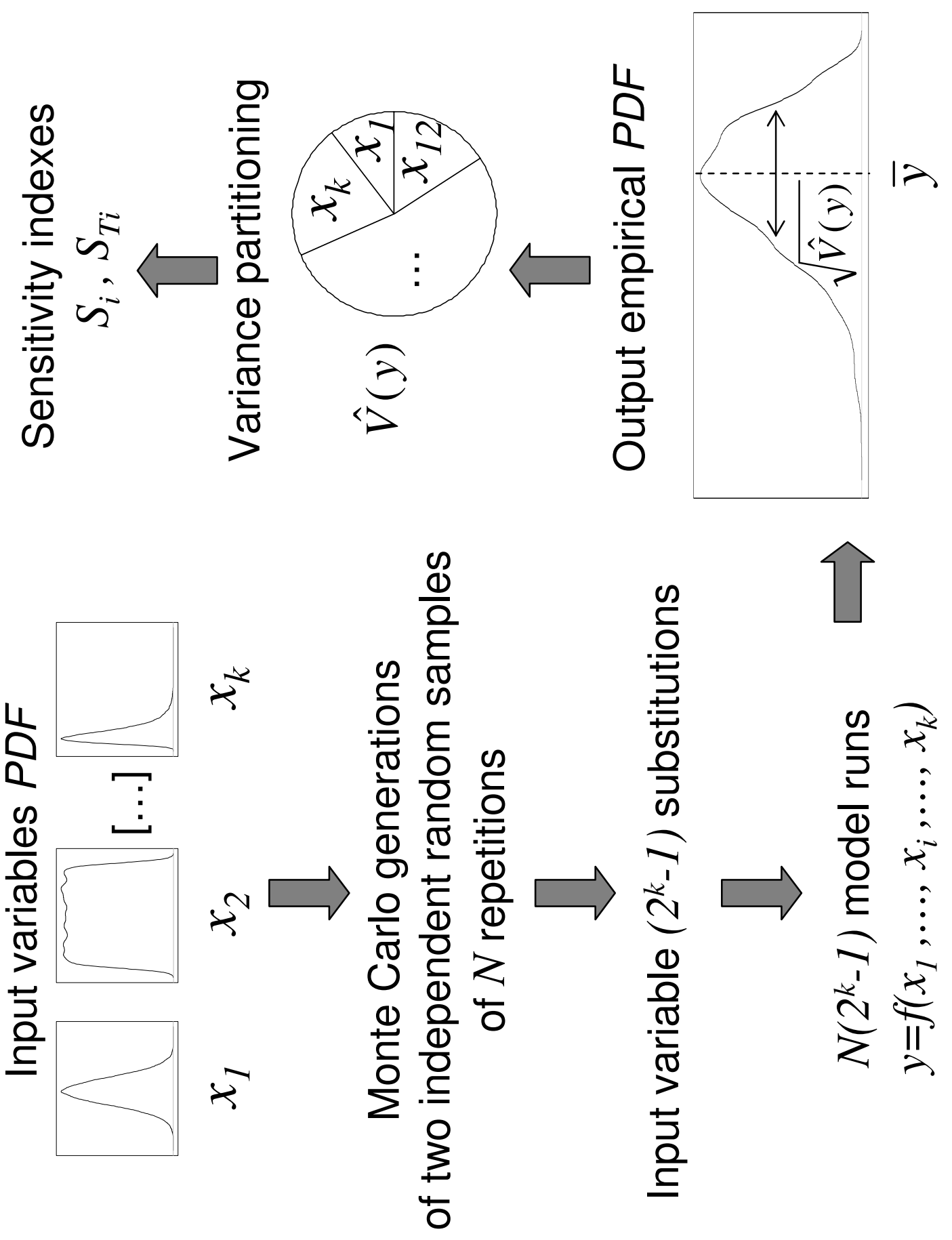


Fig 3. SA monthly indices

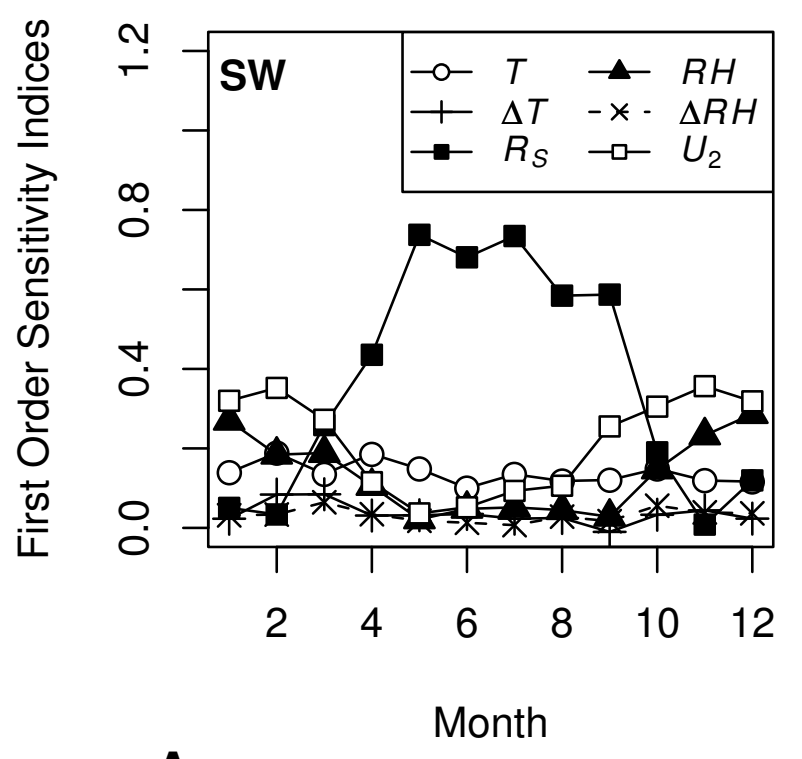

A

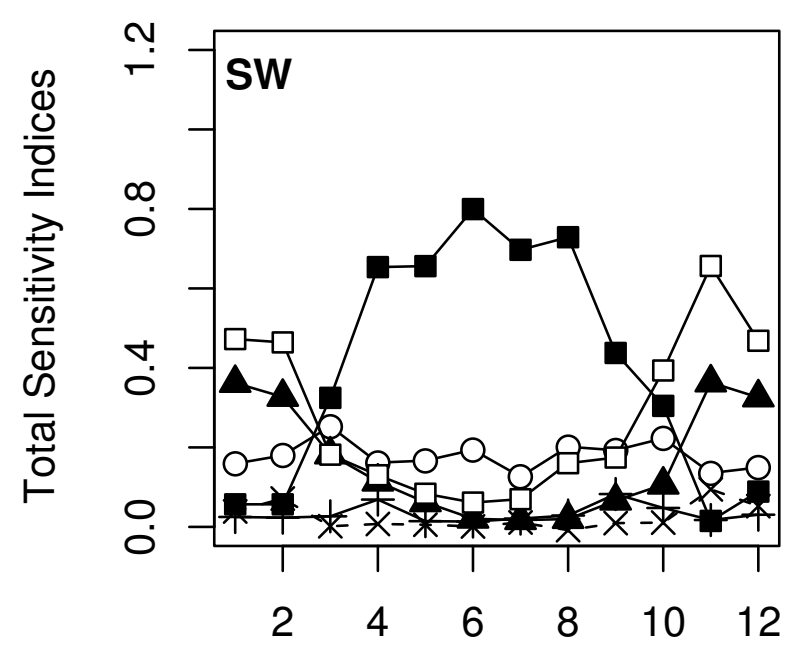

B

Month
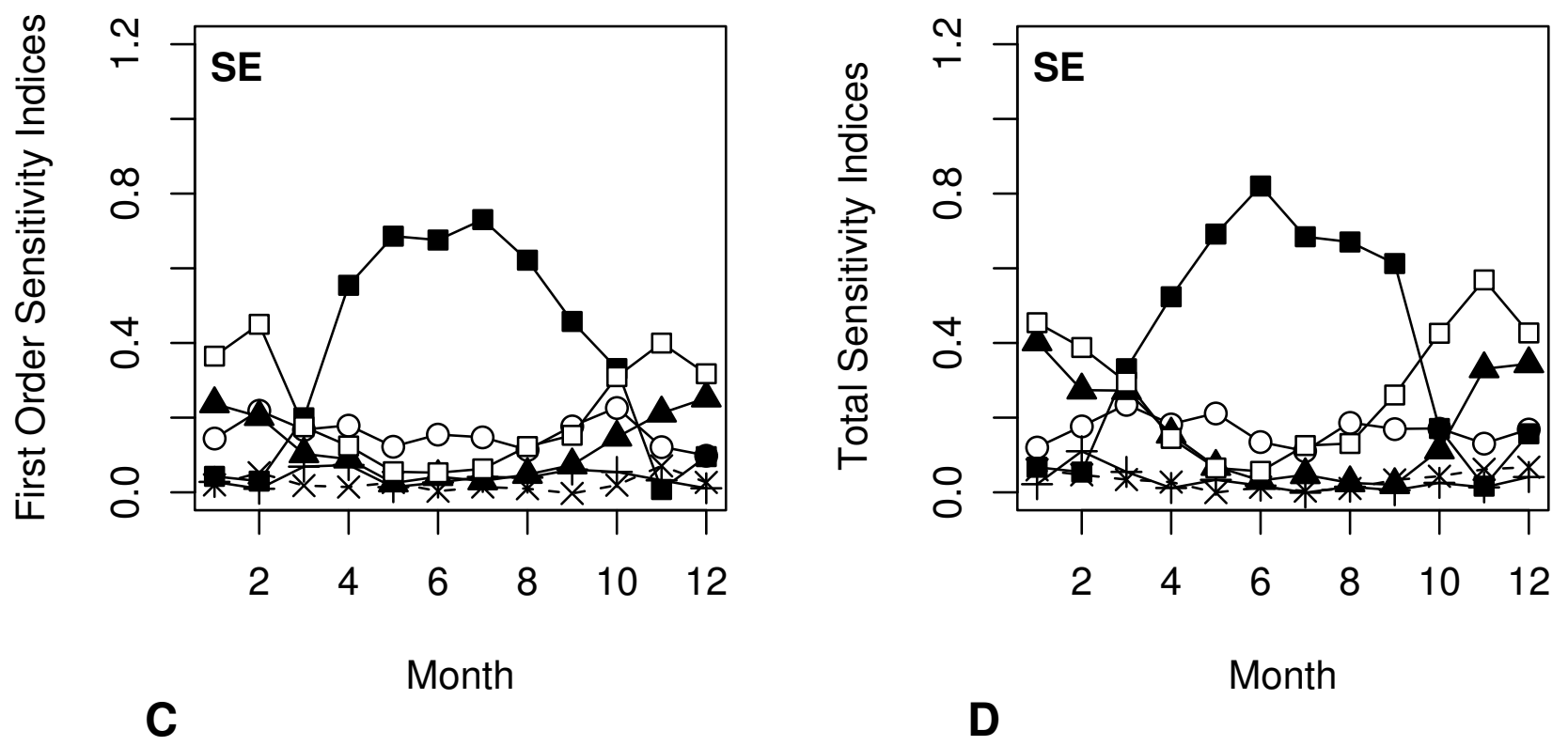


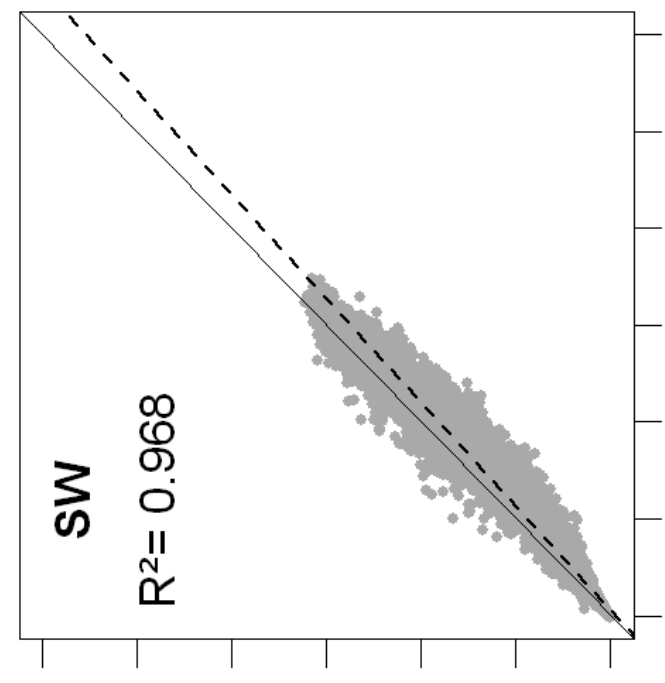

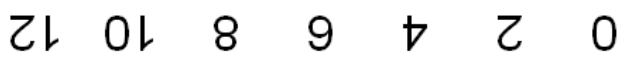

(um) łeso!!əН ${ }^{\cap \perp} \exists$

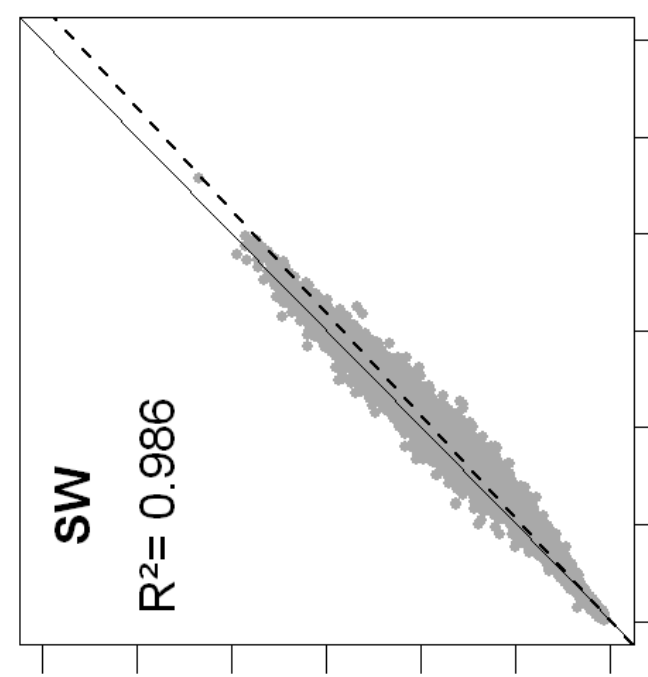

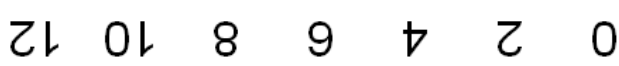

(um) łeso!

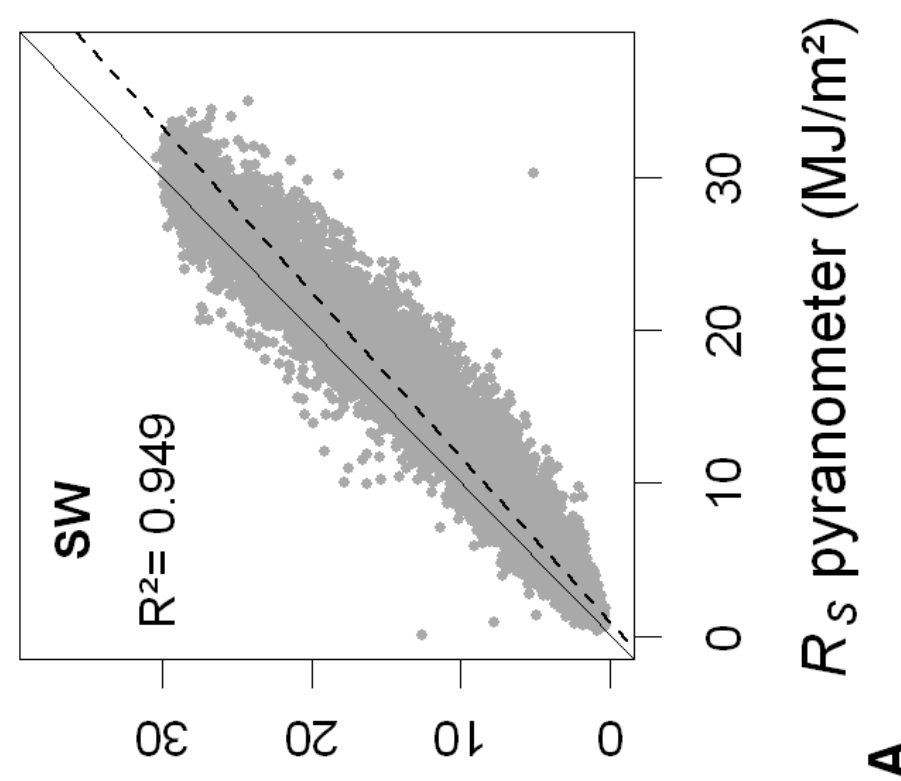

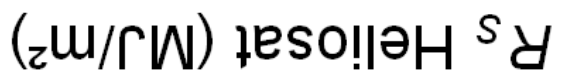

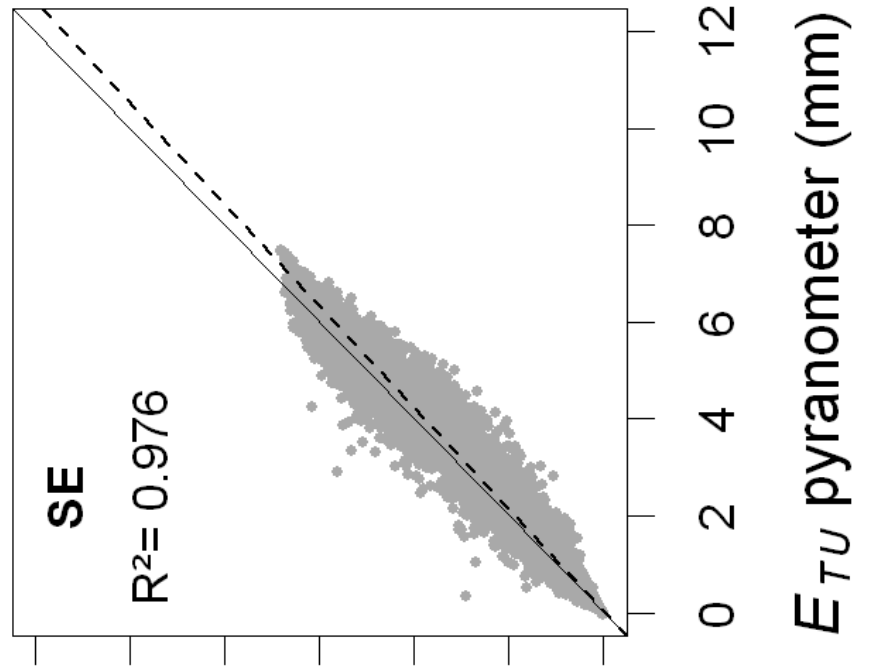

$\begin{array}{lllllll}\text { 乙L } & \text { Ol } & 8 & 9 & \nabla & \text { 乙 } & 0\end{array}$

(um) ґeso!|əH ${ }^{\cap \perp} \exists$

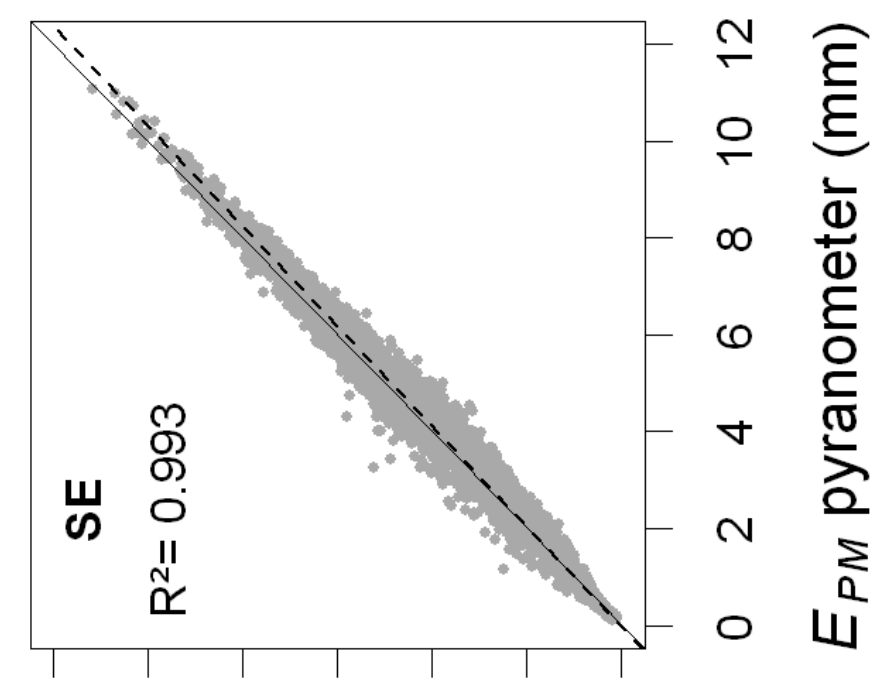

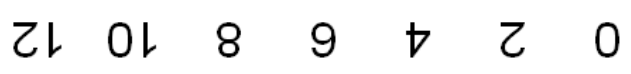

ш

(um) łeso!

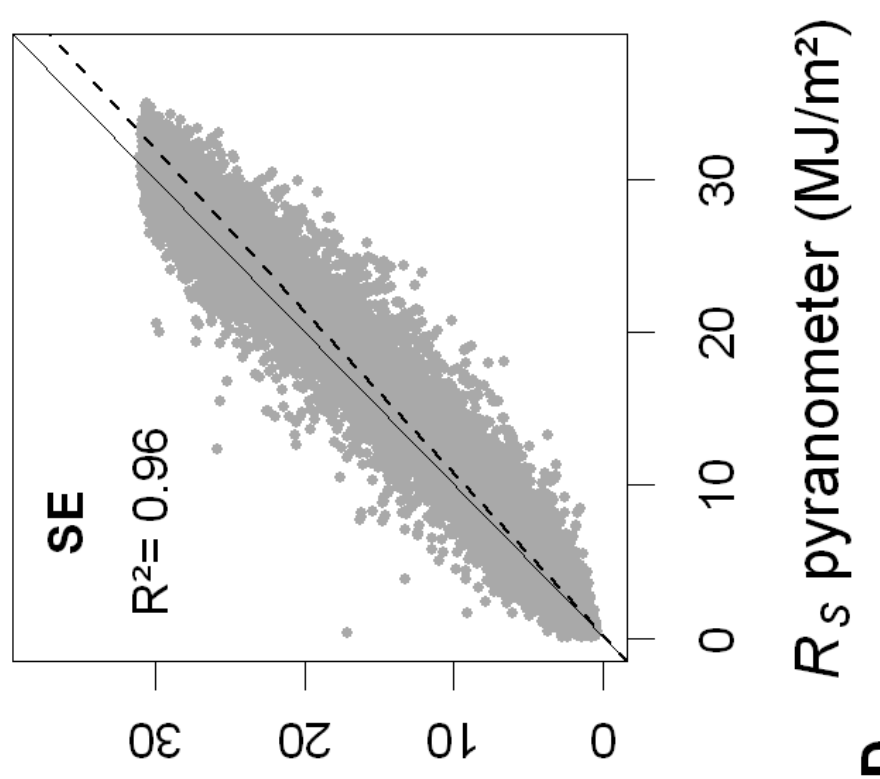

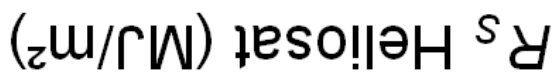




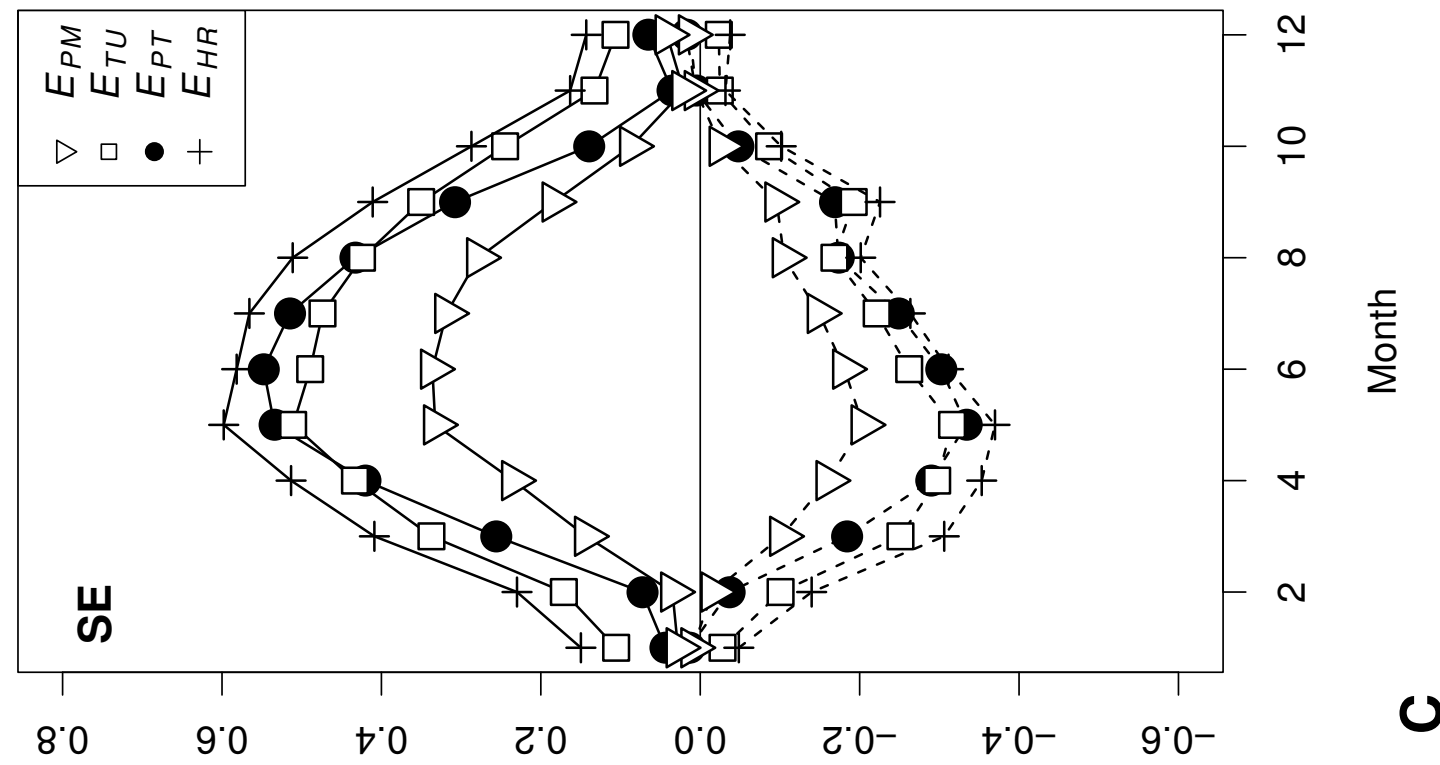

(mw) 10ג

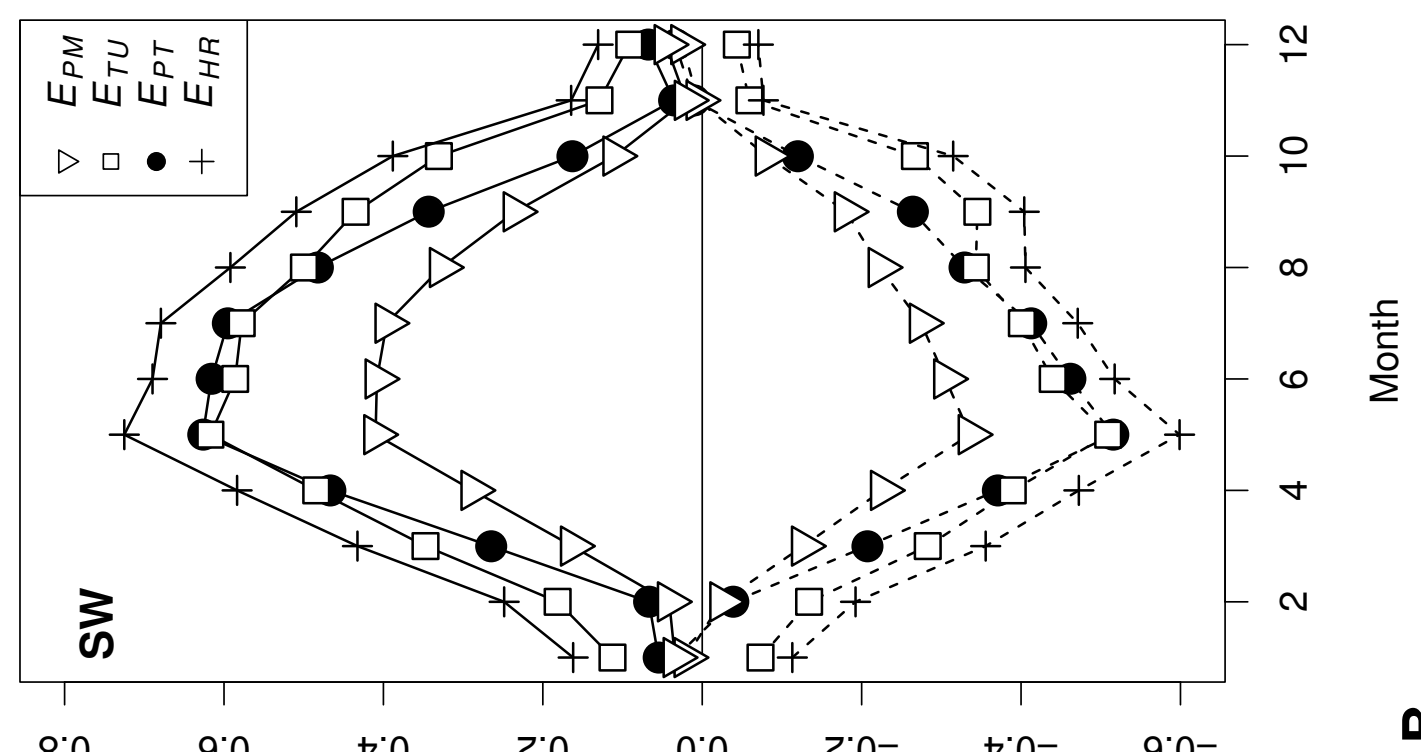

(mw) 10גנ

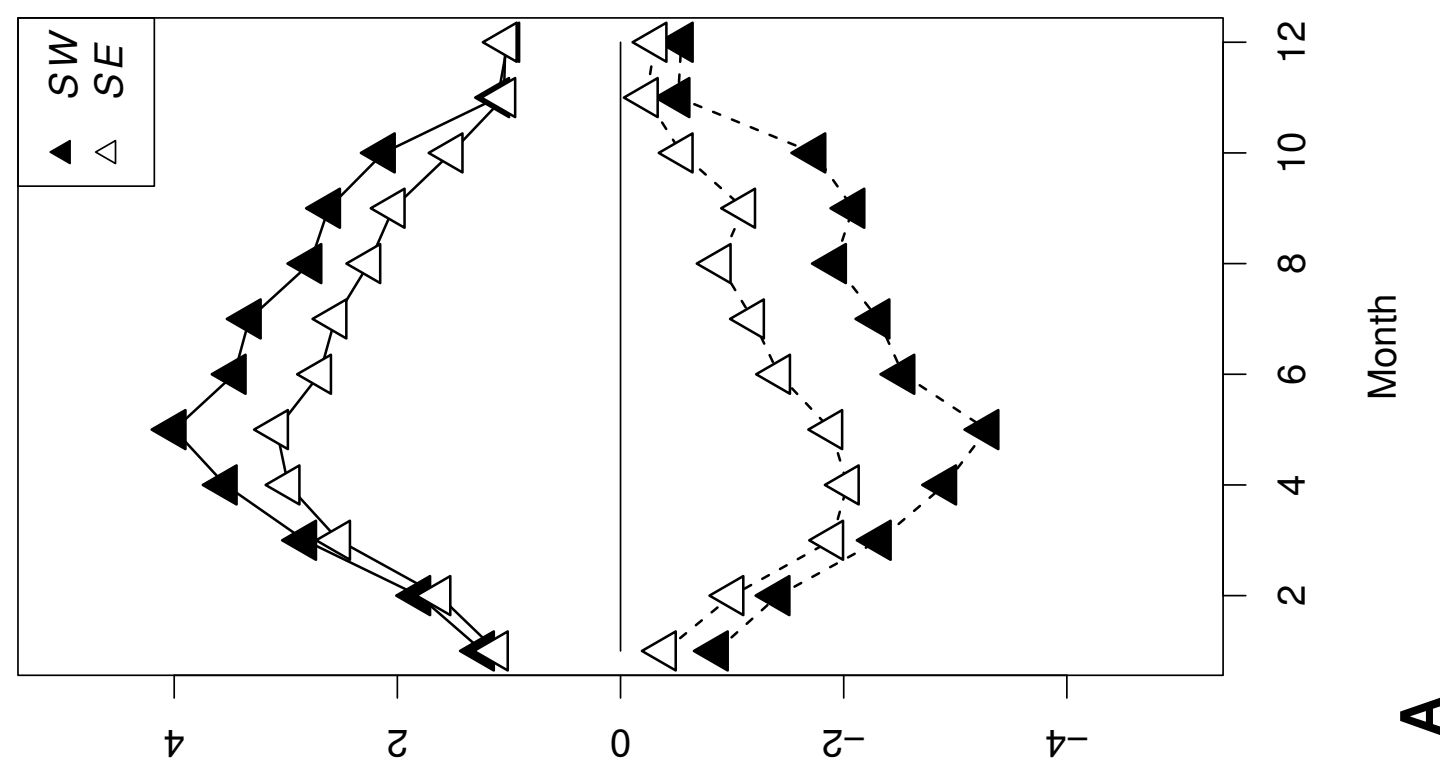

כג 

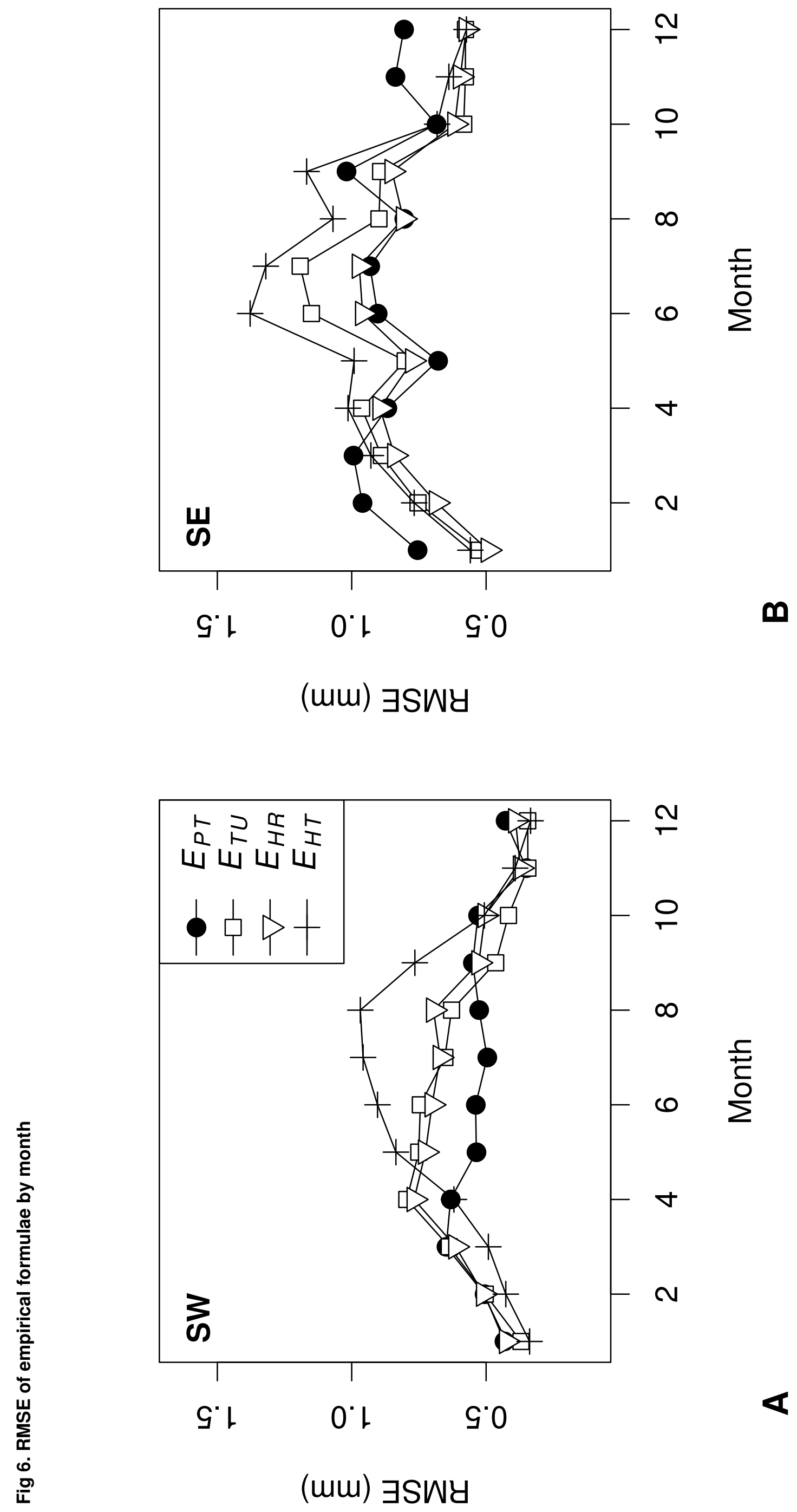
Fig. 1. Spatial distribution of the 19 meteorological stations used in the study. SW: Southwest area, SE: Southeast area.

Fig. 2. General scheme of Sobol' sensitivity analysis. $P D F=$ Probability Distribution Function. $x_{i}=$ the $i$ th variable of the model's $k$ input variables. $y=$ the model output.

Fig. 3. Monthly variations of first order and total sensitivity indices of climate input variables of $P M$ model, for reference evapotranspiration calculation. A and B: Southwest area (SW); $\mathbf{C}$ and D: Southeast area (SE).

Fig. 4. Scatter plots of pyranometer and HelioClim-1 data. A, B, C: Southwest area (SW). D, $\mathbf{E}, \mathbf{F}$ : Southeast area (SE). $R_{S}$ : daily solar irradiation ; $E_{P M}: E_{0}$ daily value with PenmanMonteith $(P M)$ method ; $E_{T U}: E_{0}$ daily value with Turc $(T U)$ method. $\quad:(1: 1)$ curve ; ----: linear fitting curve.

Fig. 5. Errors induced by the use of daily HelioClim-1 data for irradiation (A), and $E_{0}$ estimates (B: Southwest area, C: Southeast area). PM: Penman-Monteith, PT: PriestleyTaylor, $T U$ : Turc, $H R$ : Hargreaves radiation, $H T$ : Hargreaves temperature. $\quad$ : RMSE ; ----: Bias.

Fig. 6. Monthly variations of RMSE resulting from the comparison of daily $E_{0}$ between Penman-Monteith and estimation formulae (PT: Priestley-Taylor, TU: Turc, HR: Hargreaves radiation, HT: Hargreaves temperature). A: Southwest area ; B: Southeast area. 
Table 1

List of weather stations used in the study

\begin{tabular}{|c|c|c|c|c|c|c|}
\hline \# code & Site & $\begin{array}{c}\text { Latitude } \\
\mathbf{N}\left({ }^{\circ}\right)\end{array}$ & $\begin{array}{c}\text { Longitude } \\
\text { W }\left({ }^{\circ}\right)\end{array}$ & $\begin{array}{l}\text { Elevation } \\
\text { (m) }\end{array}$ & $\begin{array}{l}\text { Mean } E_{0} \\
\left(\mathbf{m m ~ d}^{-1}\right)^{\mathbf{a}} \\
\end{array}$ & $\mathbf{N}^{\mathbf{b}}$ \\
\hline & South West & & & & & \\
\hline 1 & BERGERAC & 44.855 & -0.521 & 33 & 2.34 & 1783 \\
\hline 2 & BOURRAN & 44.334 & -0.413 & 60 & 2.43 & 1606 \\
\hline 3 & CADAUJAC & 44.753 & 0.554 & 20 & 2.36 & 1827 \\
\hline 4 & LATRESNE & 44.780 & 0.478 & 63 & 2.54 & 1826 \\
\hline 5 & LUXEY & 44.226 & 0.491 & 101 & 2.30 & 1818 \\
\hline 6 & SAINT LAURENT-DE-LA-PREE & 45.990 & 1.033 & 3 & 2.46 & 1827 \\
\hline 7 & SAINT MARTIN DE HINX & 43.576 & 1.269 & 64 & 2.29 & 1826 \\
\hline \multirow[t]{2}{*}{8} & VILLENAVE D'ORNON & 44.789 & 0.578 & 25 & 2.55 & 1827 \\
\hline & South East & & & & & \\
\hline 1 & AVIGNON & 43.916 & -4.876 & 24 & 3.27 & 1827 \\
\hline 2 & BELLEGARDE & 43.781 & -4.477 & 61 & 3.15 & 1762 \\
\hline 3 & FOURQUES & 43.692 & -4.595 & 3 & 3.41 & 1826 \\
\hline 4 & FREJUS & 43.434 & -6.717 & 3 & 3.13 & 1827 \\
\hline 5 & GRUISSAN & 43.137 & -3.121 & 40 & 3.04 & 1827 \\
\hline 6 & LES-SAINTES-MARIES-DE-LA-MER & 43.580 & -4.499 & 1 & 3.23 & 1827 \\
\hline 7 & MONTPELLIER & 43.647 & -3.874 & 50 & 2.60 & 1613 \\
\hline 8 & ROUJAN & 43.491 & -3.321 & 78 & 2.45 & 774 \\
\hline 9 & SAINT-MARCEL-LES-VALENCE & 44.977 & -4.930 & 190 & 2.97 & 1827 \\
\hline 10 & SAINT-GILLES & 43.714 & -4.412 & 72 & 3.15 & 1775 \\
\hline 11 & SALON DE PROVENCE & 43.646 & -5.014 & 68 & 3.27 & 1604 \\
\hline
\end{tabular}

${ }^{\mathrm{a}} E_{0}$ was calculated with Penman-Monteith model (i.e. $\left.P M\right)$.

${ }^{\mathrm{b}}$ Number of available $E_{0}$ values (days) on the period 2000-2004. Maximum is 1827 . Lower $\mathrm{N}$ values means that data used to calculate $E_{0}$ with Penman-Monteith model (i.e. temperature, relative humidity, wind speed or solar radiation) were unavailable on certain days. 
Table 2

First order sensitivity indices of $P M$ method to climate variables. The values between brackets correspond to the relative par of total $E_{0}$ variance explained by each input variable. Figures in bold correspond to the highest sensitivity index of each month.

\begin{tabular}{lccccccc} 
& Month & $\boldsymbol{T}$ & $\boldsymbol{\Delta}$ & $\boldsymbol{R}_{\boldsymbol{s}}$ & $\boldsymbol{R} \boldsymbol{H}$ & $\boldsymbol{\Delta} \boldsymbol{H}$ & $\boldsymbol{U}_{2}$ \\
\hline \multirow{2}{*}{ South-West } & January & $0.14(17 \%)$ & $0.02(3 \%)$ & $0.05(6 \%)$ & $0.27(32 \%)$ & $0.03(4 \%)$ & $\mathbf{0 . 3 2}(\mathbf{3 8 \%})$ \\
& April & $0.19(20 \%)$ & $0.03(3 \%)$ & $\mathbf{0 . 4 4 ( 4 8 \% )}$ & $0.11(12 \%)$ & $0.03(4 \%)$ & $0.12(13 \%)$ \\
& July & $0.13(13 \%)$ & $0.02(2 \%)$ & $\mathbf{0 . 7 3 ( 7 0 \% )}$ & $0.05(5 \%)$ & $0.01(1 \%)$ & $0.09(9 \%)$ \\
\hline \multirow{2}{*}{ South-East } & January & $0.14(17 \%)$ & $0.03(3 \%)$ & $0.04(5 \%)$ & $0.24(28 \%)$ & $0.02(2 \%)$ & $\mathbf{0 . 3 6 ( 4 4 \% )}$ \\
& April & $0.18(17 \%)$ & $0.07(7 \%)$ & $\mathbf{0 . 5 5 ( 5 4 \% )}$ & $0.09(9 \%)$ & $0.01(1 \%)$ & $0.12(12 \%)$ \\
& July & $0.15(14 \%)$ & $0.04(4 \%)$ & $\mathbf{0 . 7 3 ( 7 1 \% )}$ & $0.03(3 \%)$ & $0.01(1 \%)$ & $0.06(6 \%)$ \\
\hline \hline
\end{tabular}


Table 3

Bias and RMSE resulting from the use of Helioclim-1 data instead of pyranometer data for daily solar irradiation and daily $E_{0}$ estimates, using Penman-Monteith or radiation methods.

Values between brackets are the ratio of the statistical index with the mean reference value (pyranometer solar radiation, and evapotranspiration calculated with pyranometer data).

\begin{tabular}{|c|c|c|c|c|c|c|c|c|c|c|c|c|}
\hline \multirow[b]{3}{*}{$R_{S}\left(\mathrm{MJ} \mathrm{m}^{-2}\right)$} & \multicolumn{6}{|c|}{ South-West } & \multicolumn{6}{|c|}{ South-East } \\
\hline & \multirow{2}{*}{$\begin{array}{r}\text { Mean } \\
13.48\end{array}$} & \multicolumn{2}{|c|}{ Bias } & \multicolumn{2}{|c|}{ RMSE } & \multirow{2}{*}{$\begin{array}{c}\mathbf{N}^{\mathbf{a}} \\
14566\end{array}$} & \multirow{2}{*}{$\begin{array}{c}\text { Mean } \\
15.83\end{array}$} & \multicolumn{2}{|c|}{ Bias } & \multicolumn{2}{|c|}{ RMSE } & \multirow{2}{*}{$\frac{\mathbf{N}^{\mathbf{a}}}{18997}$} \\
\hline & & -1.87 & $(-14 \%)$ & 2.67 & $(20 \%)$ & & & -1.07 & $(-7 \%)$ & 2.16 & $(14 \%)$ & \\
\hline$E_{P M}(\mathrm{~mm})$ & 2.41 & -0.14 & $(-6 \%)$ & 0.25 & $(11 \%)$ & 14308 & 3.10 & -0.08 & $(-30$ & 0.21 & $(7 \%)$ & 18448 \\
\hline$E_{T U}(\mathbf{m m})$ & 2.38 & -0.27 & $(-11 \%)$ & 0.41 & $(17 \%)$ & 14308 & 2.87 & -0.16 & $(-6$ & 0.35 & $(12 \%)$ & 18448 \\
\hline$E_{P T}(\mathrm{~mm})$ & 2.34 & -0.22 & $(-9 \%)$ & 0.39 & $(17 \%)$ & 14308 & 2.77 & -0.14 & $(-5$ & 0.34 & $(12 \%)$ & 18448 \\
\hline$E_{H R}(\mathrm{~mm})$ & 2.52 & -0.33 & $(-13 \%)$ & 0.49 & $(19 \%)$ & 14308 & 3.09 & -0.20 & $(-6 \%)$ & 0.41 & $(13 \%)$ & 18448 \\
\hline
\end{tabular}

${ }^{\mathrm{a}}$ Number of values. 
Table 4

Sources of climate variables used for reference evapotranspiration calculations in section 3.4.

\begin{tabular}{lccccc}
\hline Method & Acronym & Temperature $^{\text {Solar }}$ & $\begin{array}{c}\text { Relative } \\
\text { radiation }\end{array}$ & Wumidity & Wind speed \\
\hline Temperature Method & $H T$ & Ground $^{\mathrm{a}}$ & & & \\
\hline Radiation Methods & $P T$ & Ground & Sat $^{\mathrm{b}}$ & & \\
& $H R$ & Ground & Sat & & \\
& $T U$ & Ground & Sat & & Ground \\
\hline $\begin{array}{c}\text { Penman-Monteith } \\
\text { Method }\end{array}$ & $P M$ & Ground & Ground & Ground & \\
\hline \hline
\end{tabular}

a Ground : climate variable measured with the weather station devices.

${ }^{\mathrm{b}}$ Sat : Helioclim-1 data (for solar radiation). 
Table 5

Summary of statistical indexes of $E_{0}$ estimation methods, at daily time step. Values between brackets represent the bias and the RMSE divided by $P M$ mean values (relative bias and relative RMSE). $R^{2}$ is the coefficient of determination; $N_{S W}$ and $N_{S E}$ are the number of observations for Southwest and Southeast area, respectively. Figures in bold correspond to the best performance in $E_{0}$ estimates, according to the index considered.

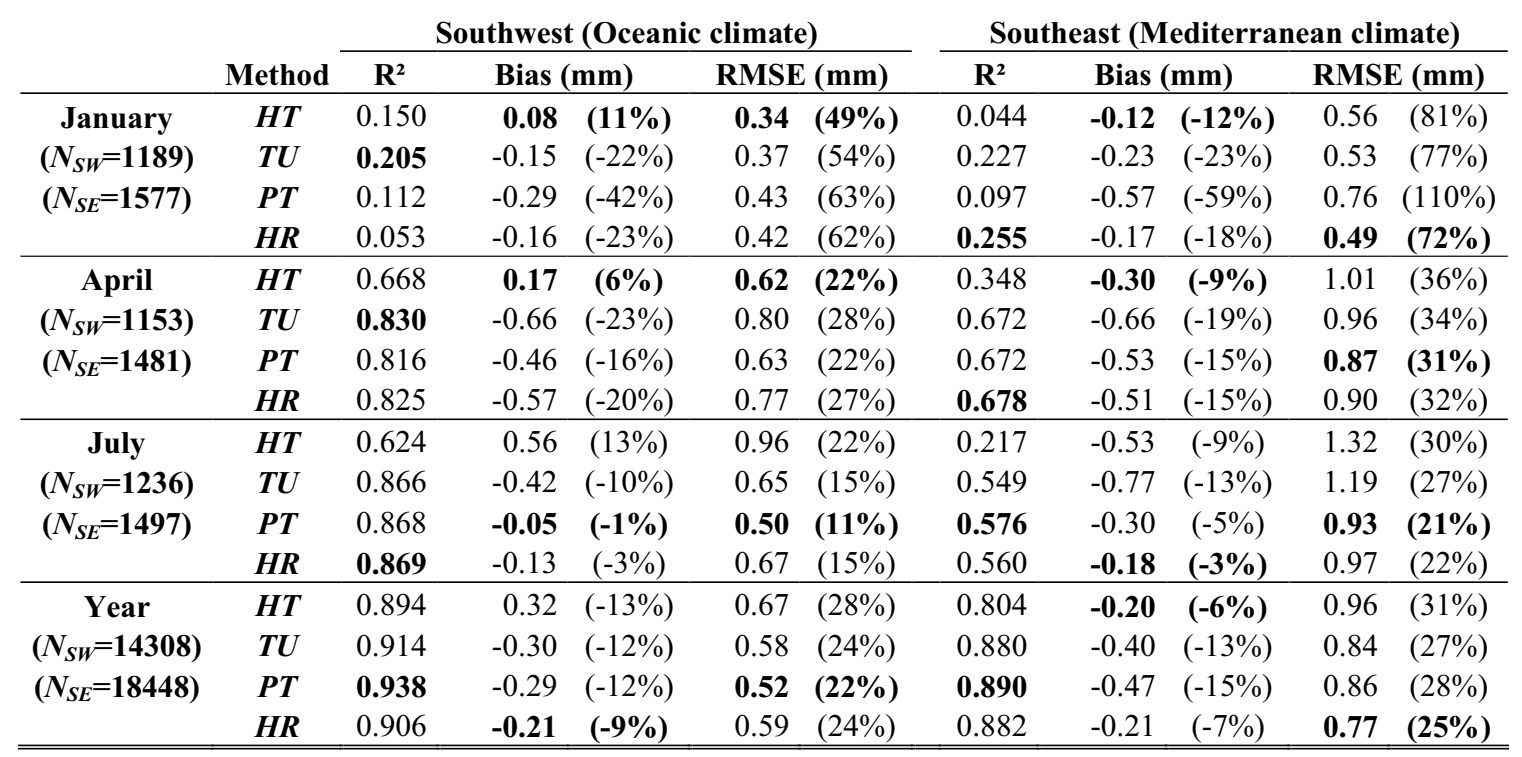

